\title{
Assessing the implementation process and outcomes of newly introduced assistant roles: a qualitative study to examine the utility of the Calderdale Framework as an appraisal tool
}

\author{
This article was published in the following Dove Press journal: \\ Journal of Multidisciplinary Healthcare \\ 5 December 2012 \\ Number of times this article has been viewed
}

\section{Susan Nancarrow' \\ Anna Moran' \\ Leah Wiseman ${ }^{2}$ \\ Alison C Pighills ${ }^{3}$ \\ Karen Murphy ${ }^{4}$}

'School of Health and Human Sciences, Southern Cross University, East Lismore, NSW; ${ }^{2}$ School of Community Health, Charles Sturt University, Albury, NSW; ${ }^{3}$ Faculty of Medicine Health and Molecular Sciences, James Cook University, Education and Research Centre, Mackay Base Hospital, Mackay, QLD; ${ }^{4}$ ACT Government Health Directorate, Canberra, ACT, Australia

Video abstract

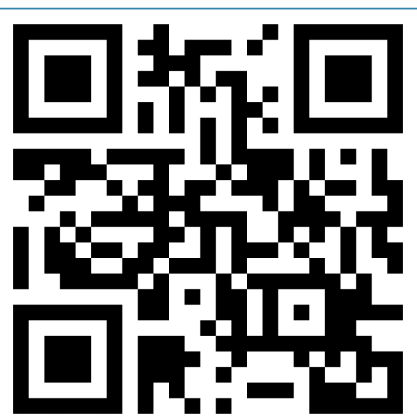

Point your SmartPhone at the code above. If you have a QR code reader the video abstract will appear. Or use: http://dvpr.es/Rjbulu

Correspondence: Susan Nancarrow School of Health and Human Sciences, Military Road, East Lismore,

NSW 2480, Australia

Tel +6I 407877973

Email susan.nancarrow@scu.edu.au
Abstract: Internationally, the health workforce has undergone rapid transformation to help meet growing staffing demands and population requirements. Several tools have been developed to support workforce change processes. The Calderdale Framework (CF) is one such tool designed to facilitate competency-based training by engaging team members in a seven step process involving awareness raising, service and task analysis, competency identification, establishing support systems, training, and sustaining. This paper explores the utility of the CF as an appraisal tool to assess whether adherence to the tool influences outcomes. The CF was applied retrospectively to three complete evaluations of allied health assistant role introduction: a new podiatry assistant role (Australia), speech pathology assistant (Australia), and occupational therapy assistant practitioner role (UK). Adherence to the CF was associated with more effective and efficient use of the role, role flexibility and career development opportunities for assistants, and role sustainability. Services are less likely to succeed in their workforce change process if they fail to plan for and use a structured approach to change, assign targeted leadership, undertake staff engagement and consultation, and perform an initial service analysis. The CF provides a clear template for appraising the implementation of new roles and highlights the potential consequences of not adhering to particular steps in the implementation process.

Keywords: workforce change, allied health, assistant practitioner, Calderdale Framework, evaluation, podiatry, occupational therapy, speech pathology

\section{Background}

The aging population and increasing rates of long-term chronic illness are placing pressures on the health workforce internationally. ${ }^{1}$ One of the implications of this change is an upward pressure on health care providers to focus on the more specialized areas of their job while delegating the less skilled components to other staff., ${ }^{2,3}$

There is increasing research into the roles of allied health assistants, and evidence suggesting that they can positively influence patient outcomes. ${ }^{46}$ The assumptions underpinning the introduction of new roles are often implicit. However, the motivation for introducing new workers is driven by a desire to increase health care accessibility, quality, effectiveness, and efficiency. ${ }^{7}$ The way the roles are implemented is an important interim step in the achievement of these outcomes.

The goal of the implementation process could be expressed as "optimizing the impact and sustainability of the implementation of an allied health assistant in the delivery of patient-centered care." ${ }^{8}$ The impact of the new roles includes increased 
service capacity, the ability to provide more direct care, more quality improvement activities, increased time for staff development activities, improved continuity of care within services, ultimately more flexibility within the workforce, and more and better client-centered care..$^{7-10}$

The relationship between the process of implementation and the impact of the new roles is illustrated by the following:

- The number and type of practitioners with whom the assistant works tends to dictate the nature and roles of the assistant's duties. Assistants who have more input from different types of workers have broader roles; ${ }^{11,12}$

- Ambiguity around the roles of the delegating practitioner and support worker leads to variations and inefficiency in delegation practice and tasks assigned to assistants. ${ }^{13,14}$ This, in turn, leads to inefficient employment of the assistant;

- The extent to which delegating staff have control over the access and content of training influences the roles of assistants by shaping the scope of the role and the willingness of the delegating staff to delegate; ${ }^{15-17}$

- The types of duties delegated to assistants are associated with greater opportunities for career advancement for the delegating staff; and

- The heterogeneity in the nature and types of roles performed by assistants limits the transferability of the assistant's skills and their employment opportunities. ${ }^{18,}$

- An important component of introducing new assistant roles is the decision process surrounding role division and task delegation. The delegation of tasks to support workers is a complex and multifaceted process which depends on a number of factors including the supervisor's personal assessment of the assistant's experience and competence and the level of trust developed with the assistant, ${ }^{16,19-24}$ the supervisor's confidence, level of experience, and clarity in their own role, ${ }^{15,25-30}$ or indeed by pragmatic, convenience-driven decisions such as who was available to respond to the particular patient need. ${ }^{31}$

There is also evidence that qualified professionals find it difficult to delegate tasks to assistants due to their sense of "professional accountability."29,32-35 Storey suggests that this concern is, in part, attributable to the fact that support workers in health care are not subject to professional registration and are therefore not professionally accountable in the same way that registered or accredited disciplines are held to account. ${ }^{34}$

Despite the complexity of the process of introducing new roles, there are only a handful of resources available to assist in efficient planning and implementation of new roles, ${ }^{36,37}$ and few that have undergone any formal evaluation. ${ }^{38}$ Consequently many new roles are introduced without the use of evidence-based, formal change management resources. A systematic review of instruments developed to facilitate workforce change and their use in practice in the UK identified 22 different instruments. ${ }^{38}$ The review analyzed each tool's development, use, and evidence of evaluation of their impact on workforce change. Few of the instruments had any published applications and none were formally validated. One tool that had been published in peer-reviewed literature and widely utilized in the implementation of new assistant roles is the Calderdale Framework (CF). ${ }^{39}$

The CF has been deployed widely in the UK and is being used in several sites in Australia to introduce new models of care. The CF emerged from a need to provide a more standardized approach to develop the role and grading of physiotherapy assistants. ${ }^{39}$ This later emerged into a delegation framework based on an understanding of the risks of delegating tasks. Given the widespread application of the $\mathrm{CF}$ in the introduction of assistant roles in the UK and Australia, it was the most appropriate tool to use in the current study.

The CF provides a framework specifically for the planning and implementation of assistant roles and interprofessional skill sharing in health and social care settings. The CF facilitates the development of competency-based training and new ways of working for support or assistant staff and their supervising practitioners by engaging team members in a seven step process. It provides a structured approach to empower staff to take ownership of workforce change processes that enable workforce shifts. The seven steps are: (1) awareness raising, (2) service analysis, (3) task analysis, (4) competency identification, (5) supporting systems, (6) training, and (7) sustaining. ${ }^{39}$ Furthermore, the CF has been shown to positively affect productivity, risk management, service planning, and staff satisfaction when new assistant roles are introduced. ${ }^{40}$ The $\mathrm{CF}$ is designed to be delivered by facilitators trained specifically in the approach. It provides a structured way of empowering staff to take ownership of workforce change processes.

Given the myriad of factors involved in the implementation of new roles and the impact these may have on the final success of the workforce change, this research explores the $\mathrm{CF}$ as a tool to appraise the implementation process and outcomes of newly introduced assistant roles in Australia and the UK, where no formal workforce development approaches were utilized. At the time of publication, no other tool was being utilized routinely in allied health assistant workforce 
change in Australia, and there are no published accounts of similar studies.

For the purpose of this paper, an assistant practitioner is a worker who competently delivers health and/or social care to and for people. They have a required level of knowledge and skill beyond that of the traditional healthcare assistant or support worker. The assistant practitioner would be able to deliver elements of health and social care and undertake clinical work in domains that have previously only been within the remit of registered professionals. The assistant practitioner may transcend professional boundaries. ${ }^{41}$

\section{Methods}

This study involved the secondary analysis of three completed evaluations of approaches used to develop assistant roles $^{1}$ in community health settings (Table 1). The three projects were selected on the basis that they each evaluated the implementation processes, demonstrated different levels of success, and have detailed written reports available. None had used an explicit workforce change tool in the implementation of the new role. The evaluations reflect the experience of the introduction of assistants in three disciplines: podiatry, speech pathology, and occupational therapy in Australia and the UK. This provides a diversity of professional applications and international insights for comparison and assessment of the $\mathrm{CF}$ as a tool to appraise other approaches to implementing new roles.

An analytical template was developed by dividing the $\mathrm{CF}$ into the seven stages with the key components of each stage as subheadings. ${ }^{39}$ These were entered into an Excel ${ }^{\circledR}$ spreadsheet (Microsoft Corporation, Redmond, WA). This template formed a framework to theme and extract the data from the three projects, akin to Ritchie and Spencer's framework approach. ${ }^{42}$ Explanatory data were then extracted from each of the evaluations to explore the effect of adhering to (or not) each of the domains of the CF. The findings were independently reviewed and verified by a CF trained practitioner (AP). Success was defined in terms of outcomes identified by participants in each study.

Ethics approval was not sought as this research reports the secondary analysis of existing data that had prior ethical approval. Only deidentified data were used for the analyses.

\section{Results}

Table 2 outlines the key stages of the CF, and summarizes the extent to which each level of the CF was completed by each new role project. Figure 1 complements Table 2 in outlining the participant identified outcomes for the three new roles. The results are presented descriptively according to the $\mathrm{CF}$

Table I Overview of new roles projects

Project I: The implementation of a speech pathology assistant utilizing a traineeship approach.

Workforce change tool employed: No

Setting: Rehabilitation, aged, and community care service within an Australian metropolitan health directorate.

Roles: Delivering group therapy, direct client contact, indirect client contact, file reviews and preparation of files, resource preparation, and administration.

Methodology: Mixed methods: interviews with key stakeholder groups involved in the development and delivery of the role, including the speech pathology assistant $(n=1)$, service users and their carers $(n=5)$, speech pathologists who worked with the trainee speech pathology assistant $(n=3)$, and managers involved in the development and implementation of the role $(n=5)$. Documentary evidence provided by the training institute and a time use analysis were included.

Project 2: The implementation of a podiatry assistant utilizing a traineeship approach. The podiatry assistant was introduced to replace enrolled nurses performing basic foot care.

Workforce change tool employed: No

Setting: Community health and continuing community care service within an Australian metropolitan health directorate.

Roles: Provision of basic foot hygiene (eg, wiping down of the feet, cutting of nonpathological nails, filing of rough skin, and applying cream), assist in nail surgery, do basic modifications to orthotics, padding, and strapping.

Methodology: Qualitative interviews with key stakeholder groups involved in the development and delivery of the role, including the podiatry assistant $(n=1)$, service users $(n=5)$, a consumer group $(n=3)$, podiatrists who worked with the podiatry assistant $(n=3)$, enrolled nurses who had previously performed the role $(n=3)$, and nursing and allied health managers $(n=5)$.

Project 3: The introduction and evaluation of an assistant practitioner in occupational therapy. ${ }^{9}$

Workforce change tool employed: No

Setting: A new transition/intermediate care service within an English Primary Health Care Trust.

Roles: The assistant practitioners work autonomously and manage their own caseload. Assistant practitioners could perform most of the roles undertaken by the qualified occupational therapists, with the exception of discharge home visits.

Methodology: A qualitative evaluation of the assistant practitioner role was undertaken 2 years after its introduction. Focus groups were held with four groups of key stakeholders including assistant practitioners (five of a possible seven); supervising occupational therapists (five of a possible seven); service managers (four of a possible six), and service users from the occupational therapy patient panel $(n=3)$. 
Table 2 Population of the Calderdale Framework using new role data

\begin{tabular}{|c|c|c|c|}
\hline \multirow[t]{2}{*}{ Calderdale Framework } & \multicolumn{3}{|c|}{ Role implemented } \\
\hline & PA & SPA & OTAP \\
\hline \multicolumn{4}{|l|}{ I. Awareness raising $\rightarrow$ staff engagement } \\
\hline I.I Managers and clinical staff engaged with processes & I & 2 & 2 \\
\hline 1.2 Whole team/service aware of and educated in the implementation process & I & 2 & 0 \\
\hline $\begin{array}{l}\text { I.3 A clear leader/clear leadership ("champion") with skills to lead and facilitate the implementation process } \\
\text { and "project manage" }\end{array}$ & 2 & 2 & I \\
\hline I.4 Leader is supported by a project lead and others undertaking similar workforce change projects & 2 & 2 & 0 \\
\hline \multicolumn{4}{|l|}{ 2. Service analysis $\rightarrow$ potential to change } \\
\hline $\begin{array}{l}\text { 2.I Frontline clinical staff identify and clarify the purpose of their service and all the functions that are carried } \\
\text { out in order to deliver this service }\end{array}$ & 0 & I & I \\
\hline 2.2 Functions are broken into tasks and these are matched to patient needs & I & I & 0 \\
\hline \multicolumn{4}{|l|}{ 3. Task analysis $\rightarrow$ risk management } \\
\hline $\begin{array}{l}\text { 3.I Open discussion with clinicians regarding suitability of tasks for delegation, identifying what and where } \\
\text { risks will occur if delegating a given task (using the Calderdale Framework decision table and risk rating } \\
\text { scale), and also how much training would be needed for each task }\end{array}$ & I & 2 & I \\
\hline \multicolumn{4}{|l|}{ 4. Competency generation $\rightarrow$ quality } \\
\hline $\begin{array}{l}\text { 4.I Tasks accepted as suitable to delegate are written into a "competency" format, which sets out } \\
\text { the performance criteria of the task }\end{array}$ & 2 & 2 & 2 \\
\hline 4.2 Clinicians agree on how task is to be performed, embedding best practice & 1 & 2 & I \\
\hline \multicolumn{4}{|l|}{ 5. Supporting systems $\rightarrow$ governance (is the workplace able to manage the new roles?) } \\
\hline 5.I Ensuring clinical supervision processes are in place & I & 2 & 2 \\
\hline 5.2 Ensuring reflective practice is encouraged for all staff (including assistants) & I & 2 & 2 \\
\hline 5.3 Ensuring personal development review processes are in place & I & 2 & 0 \\
\hline 5.4 Ensuring communication channels are clear and robust & 2 & 2 & I \\
\hline \multicolumn{4}{|l|}{ 6. Training $\rightarrow$ staff development } \\
\hline 6.I Training developed for both qualified and support staff & I & I & 0 \\
\hline 6.2 Support staff trained in competencies, each comprising a knowledge-based element and a practical element & 2 & 2 & 2 \\
\hline $\begin{array}{l}\text { 6.3 Support staff also trained so they understood what feedback to give, when and how to give it, and when } \\
\text { a task should be halted }\end{array}$ & 0 & 2 & 0 \\
\hline 6.4 Competence assessed prior to performing on a patient & 2 & 2 & 0 \\
\hline 6.5 Training in core competencies first. Once competent, then more specific competencies are introduced & 2 & 2 & 0 \\
\hline $\begin{array}{l}\text { 6.6 Qualified staff were trained so all understood how the competencies were derived and what the support } \\
\text { staff were competent to perform }\end{array}$ & 0 & 2 & 0 \\
\hline \multicolumn{4}{|l|}{ 7. Sustaining $\rightarrow$ embedding and monitoring } \\
\hline 7.I Resulting "framework" embedded into local induction and personal development review for new members of staff & 0 & I & 0 \\
\hline 7.2 Audit plan developed to monitor outcomes and use of competencies & 0 & 2 & 0 \\
\hline
\end{tabular}

Notes: 0 , criterion was not met at all; I, criterion was only partly met (where only part of the stage/process has been completed. For example, only a selection of staff were consulted with and engaged in the implementation process for the podiatry assistant role, champions were not identified, and project planning was not formally deployed); 2, criterion was fully met.

Abbreviations: OTAP, occupational therapy assistant practitioner; PA, podiatry assistant; SPA, speech pathology assistant.

headings, then in terms of the relationship between adherence to the $\mathrm{CF}$ and the outcomes for each of the projects.

\section{Awareness raising}

Stage one of the CF (awareness raising) incorporates the need for staff engagement, consultation, and leadership. This stage also specifies the need for a clear strategy to be determined, documented, championed, and shared with all stakeholders, even those external to the immediate clinical setting where the role will be introduced. The timeliness of engaging stakeholders was identified as an important element for successful implementation of this stage.
The podiatry assistant (PA) project, for example, did not systematically plan or formalize the steps taken in the implementation of the role. This compromised the sustainability of the program. The development of the role was extremely time intensive, requiring large amounts of podiatrist time to deliver education, supervision, and training. The impact of not systematizing the implementation was that there was no track record or paper trail of the key contextual elements required for replication or expansion of the new role, other than the competencies and scope of practice policies that were developed. This lack of project sustainability was clearly identified in the CF by the inability to populate information 


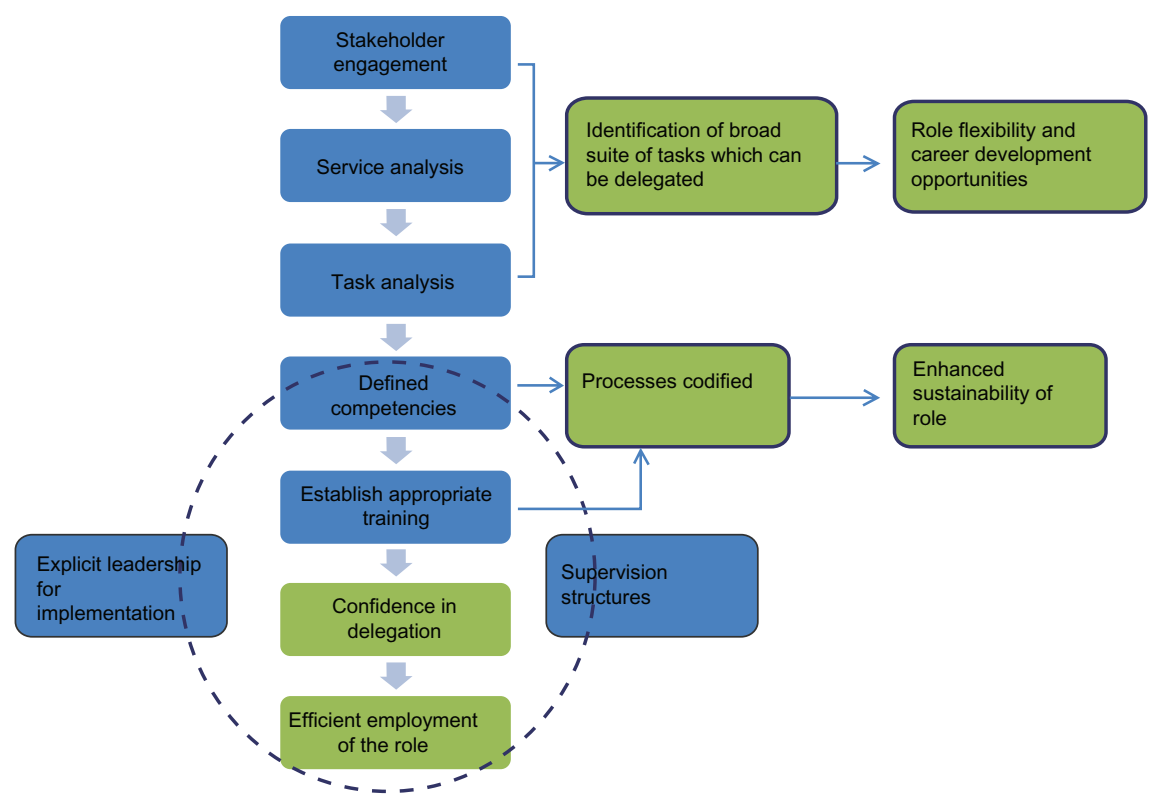

Figure I Relationship between the processes of assistant practitioner implementation and outcomes. Note: Blue boxes denote processes; green boxes denote outcomes.

against any elements contained in CF stage seven (sustaining, embedding, and monitoring).

In contrast, the speech pathology assistant (SPA) project incorporated all elements required in stage one, resulting in joint learning and joint ownership of the process and of development of the role. By the time the new role was introduced, team members were ready for the new post and had clear expectations of the trainee.

The lack of whole team awareness of and engagement in the implementation of the occupational therapy assistant practitioner (OTAP) role created ambiguities in the role interface between the assistant practitioners and the qualified therapists. This negatively affected the implementation process, the efficient use of the role, and the satisfaction of the assistant staff.

\section{Service analysis}

Service analysis plays a crucial role in determining the success of the remaining five stages. None of the teams fully met this criterion. The lack of a service analysis made it difficult for services to accurately identify service functions and break them down into their constituent tasks. As a consequence, services were unable to then objectively identify suitable tasks for delegation through staff consensus (stage three), develop competencies (stage four), identify and embed supervision and support systems and professional development opportunities (stage five), provide training (stage six), and finally to enable future development of the role (stage seven).

\section{Task analysis}

Task analysis involves discussions with the clinicians around the suitability of tasks for delegation, the risks of delegating those tasks, and the training required. An effective task analysis is dependent on having appropriate staff engagement (stage 1), and an understanding of the service requirements (stage two).

The interdependence of these stages is subtly demonstrated in the PA project. For example, flexibility is built into the $\mathrm{CF}$ by facilitating objective, consensus-based decisions around the choice of tasks to be delegated (stage three), and construction of competencies (stage four). However, these stages were only partially completed in the PA project, resulting in little flexibility of the PA role. The assistant's role was very tightly prescribed and the evaluation showed that the benefits of working within a clearly defined scope of practice, such as having confidence in the new role, were offset by the reduced flexibility of the role to fill gaps in service delivery. The rigid scope of practice also limited the opportunities for expansion and career progression of the role. This was compounded by the fact that the key components of stage five (supporting systems) were only partially undertaken. Supporting systems appear to be crucial in gaining staff and organizational ownership to actively implement governance systems to make the new roles safe for patients and acceptable to staff.

In contrast, the lack of formal task analysis meant that there was little clarity around the scope of practice 
for the new OTAP role leading to ambiguous role boundaries. $^{32}$ This was because staff were not engaged (stage one) in a comprehensive service analysis to identify the exact functions of the service (stage two) combined with a lack of "in-house" competency development (stage four).

\section{Competency generation}

All three new role projects resulted in the development of new competencies; however, these were achieved in different ways. The SPA project developed competencies through a task analysis, and in consultation with the supervising practitioners.

The OTAP project relied on the development and delivery of some of the competency training by an external agency, which was not specifically tailored for the needs of the service or the role.

\section{Supporting systems}

The supporting systems involve the development of formal supervision, reflective practice, personal development review processes, and ensuring clear communication channels. The SPA project established clear formal and informal supervision networks for all staff who worked with the SPA. This provided valuable support for the implementation of the role for staff at all levels. Risks and responsibilities were clearly understood and defined. As a result, supervising staff were confident to delegate tasks with the understanding that they were responsible for the outcome.

The extent of the supervision and support structures were less well formalized in the OTAP and PA projects. In the OTAP project, there was some confusion as to the lines of responsibility and accountability of the OTAP. This meant that staff were unsure of who bore the risks for delegation, reducing the likelihood of appropriate delegation of roles. The PA project used established supervision protocols; however, they were less formalized and embedded in practice than the SPA project. There was little ambiguity around the scope of practice, however. In all cases, the assistant practitioners were confident in their own boundaries and limits and were comfortable accessing appropriate support or supervision when required.

\section{Training}

All projects provided training using a blend of in-house training with externally provided formal training. The services developing the SPA and PA roles worked closely with a local training organization to develop bespoke training which would meet the needs of the local context. In contrast, the OTAP training was provided by an external organization which provided generic health care skills that were largely deemed to be inappropriate for the OTAP role.

The level of involvement of the supervising staff in the development of the training and competencies was key to their appropriate delegation to the assistants (Table 2), but only occurred fully with the SPA.

The type of assistant tasks influenced the development and implementation of competencies. Where the SPA and PA roles were more "task"-based, the OTAP role included a great deal of "enablement" and focused more around the relationship between the OTAP and the client. This affects stage 6.5 , which proposes the serial development of competencies (Table 2).

None of the allied health staff received formal training in the supervision of support staff, although the SPA and PA supervisors were trained to supervise students and they were able to translate this to assistant supervision.

\section{Sustaining}

Only the SPA project introduced the assistant role into formal induction procedures and developed a structured plan to audit the approach; however, all projects were formally evaluated. The roles have been continued in all cases and embedded within normal practice.

\section{The relationship between adherence to the CF and outcomes}

Broadly, the success of the introduction of the new roles was captured in three key outcomes:

1. The effective and efficient use of the assistant role;

2. Role flexibility and career development opportunities; and

3. The sustainability of the role.

The way CF demonstrates a link between the process of implementation and outcomes is described below and illustrated in Figure 1.

\section{Effective and efficient use of the role}

The lack of whole team awareness of and engagement (stage one) in the implementation of the OTAP role combined with a lack of clear clinical leadership for the introduction of the role eventually led to ambiguities in the role interface between the assistant practitioners and the qualified therapists.

The ambiguity around the scope of practice for the new OTAP role led to the need for role negotiation between 
occupational therapists and OTAPs and perceived role threat among occupational therapists (Table 3). Using the CF to identify how this may have occurred, staff were not engaged (stage one) in a comprehensive service analysis to identify the exact functions of the service (stage two), a comprehensive task analysis was not completed (stage three), and there was a lack of "in-house" competency development (stage four).

Although "appropriate" tasks were identified to allocate to the OTAP, there was a lack of objectivity in decision making leading to ambiguity of scope (stage three). "Competency development" was performed and delivered by an external training organization. A lack of understanding of the content provided by the external training organization, the health service where the new role would be implemented, and staff (stage six) resulted in distrust between the supervising practitioners and OTAPs because the qualified staff were not aware of the content of training the assistants received (stage seven). Consequently the supervising practitioners judged the competence of the assistant practitioner through "gut feeling" and the relationships they had developed with practitioners rather than through having a clear understanding of the competencies they had developed through training. This ultimately compromised the success of the implementation process in terms of poor levels of sustainability, poor staff satisfaction with the new role, and consequently the inability to realize the role's full potential (Table 3 ).

\section{Role flexibility and career development opportunities}

Flexibility is built into the CF by facilitating objective, consensus-based decisions around the choice of tasks to be delegated (stage three) and construction of competencies (stage four). The ability to comprehensively undertake these two stages is influenced by the undertaking of service analysis (stage two) whereby clinical staff identify and clarify the purpose of their service and all the functions that are carried out in order to deliver this service. However, these stages were only partially completed in the PA project, resulting in little flexibility of the PA role. The assistant's role was described as "a lot of the same" and participants identified that the benefits of working within a clearly defined scope of practice, such as having confidence in the new role, were offset by the reduced flexibility of the role to fill gaps in service delivery and limited career progression opportunities of the role.

Limited career progression opportunities were also identified for the SPA. This may be partly due to insufficient investment undertaking stage two service analyses whereby identifying the purpose of the service and the functions carried out to deliver the service can provide an objective view of areas an assistant may be able to operate in, not considered previously.

\section{Sustainability}

The importance of codifying practice for the ongoing sustainability of the role was illustrated in the PA project. The PA project did not systematically plan or formalize the steps taken in the implementation of the role (stage one), yet the development of the role was extremely time intensive, requiring large amounts of podiatrist time to deliver education, supervision, and training. The impact of not systematizing the implementation was that there was no track record or paper trail of the key contextual elements required for replication or expansion of the new role other than the competencies and scope of practice policies that were developed. This lack of project sustainability was clearly identified in the CF by the inability to populate information against any elements contained in CF stage seven (sustaining, embedding, and monitoring).

\section{Facilitators for successful implementation of new assistant roles}

By mapping the three evaluations to the $\mathrm{CF}$, it was possible to identify explicit enabling features from the three projects that were key to facilitating successful implementation of new assistant roles. As detailed in Table 3, many of these features are embedded within the different stages of the CF. Specific facilitators included:

- Organizational features, such as a recruitment strategy that reflects the needs and attributes of the organization, the workplace, the team, the tasks required of the assistant, and identifying contextual factors that may help or hinder the implementation process;

- Defining key relationships that are required for successful implementation of new roles, for instance with training organizations, professional bodies, and other key stakeholders or services;

- Identifying and securing resources required for the implementation process, such as backfill;

- Matching the overall implementation plan with national, state, local, and professional strategic directions; and

- Identifying key attributes required of the assistant, team, and specific team members such as the change leader and those responsible for training the assistant. 
Table 3 Barriers and facilitators to successful implementation of assistant roles

\begin{tabular}{|c|c|c|}
\hline & Barriers and facilitators & Stage of CF \\
\hline \multicolumn{3}{|l|}{ Organizational } \\
\hline Timing & $\begin{array}{l}\text { Implementation of roles was not well timed with training } \\
\text { organization (PA) The OTAP role was introduced at the } \\
\text { same time as new services were being developed (OTAP) }\end{array}$ & $\begin{array}{l}\text { Stage I: incorporates project planning and project } \\
\text { management elements around time lines/time frames and } \\
\text { key dates for implementation }\end{array}$ \\
\hline Overall strategy & $\begin{array}{l}\text { An overall strategy / approach was not identified prior to } \\
\text { the implementation (PA, SPA and OTAP) }\end{array}$ & $\begin{array}{l}\text { Stage I: assists staff to plan the change management } \\
\text { process }\end{array}$ \\
\hline Recruitment & $\begin{array}{l}\text { Targeted recruitment strategy was key to success of } \\
\text { the role (SPA and PA) Managers suggested succession } \\
\text { planning for OTAP staff through targeted recruiting in } \\
\text { non-health area }\end{array}$ & $\begin{array}{l}\text { Stage 7: Competency based role descriptors are written } \\
\text { that can then be used for recruitment process. }\end{array}$ \\
\hline $\begin{array}{l}\text { Organizational and } \\
\text { team culture }\end{array}$ & $\begin{array}{l}\text { The implementation of the PA role involved managing } \\
\text { the cultures of two different organizations (training } \\
\text { organization and the health service). The culture of } \\
\text { the organization was perceived as supportive to the } \\
\text { introduction of the new role (SPA). An innovative } \\
\text { and flexible working environment enhanced the } \\
\text { implementation of the OTAP role. }\end{array}$ & $\begin{array}{l}\text { Stage I: works with staff to identify key contextual factors } \\
\text { that may or may not facilitate the implementation process, } \\
\text { including discussion around local, state wide and national } \\
\text { barriers and drivers }\end{array}$ \\
\hline $\begin{array}{l}\text { Classification of } \\
\text { roles/pay }\end{array}$ & $\begin{array}{l}\text { Delay in Industrial classification of new roles led to a } \\
\text { delay in recruiting, paying and providing initial training } \\
\text { for the PA. Split industrial classification led to two tiered } \\
\text { industrial relations system (PA and SPA). }\end{array}$ & $\begin{array}{l}\text { Stage I: includes identification of facilitators and barriers } \\
\text { and also discussion and planning around the targeted grade } \\
\text { the new role will be. Stage } 7: \text { facilitates identification of key } \\
\text { areas for sustainability e.g. need for negotiation at a higher } \\
\text { level for new roles to be created. }\end{array}$ \\
\hline Resourcing & $\begin{array}{l}\text { Protected time to allow staff to perform all stages of } \\
\text { implementation (including planning and engagement). Lack } \\
\text { of this led to high workload levels and lack of engagement } \\
\text { of all stakeholders }\end{array}$ & $\begin{array}{l}\text { Stage I: incorporates project identification of what } \\
\text { resources will be required of and provided by the } \\
\text { organization to support the implementation process. Stage } \\
\text { 6: plans training resources. }\end{array}$ \\
\hline \multicolumn{3}{|l|}{ Attributes } \\
\hline Of the assistant & $\begin{array}{l}\text { Personal traits of the assistant: specifically, maturity, } \\
\text { flexibility, adaptability, fits well into the team; should } \\
\text { know their own boundaries and capabilities and not } \\
\text { exceed these boundaries; well-developed insight with } \\
\text { regard to their skill set and role boundaries }\end{array}$ & $\begin{array}{l}\text { Stages I, } 3 \text { and } 4 \text { : facilitation of what attributes are } \\
\text { required of the assistant. These attributes are then written } \\
\text { into role descriptions (stage I). Every competency requires } \\
\text { an understanding of the specific skills and attributes a } \\
\text { worker needs to perform their role competently (stage 4). }\end{array}$ \\
\hline Of the team & $\begin{array}{l}\text { Managers and the team needed to be innovative and } \\
\text { flexible while remaining committed to clinical governance. } \\
\text { Team members needed to embrace 'modern ways of } \\
\text { working' and be willing to try new things }\end{array}$ & $\begin{array}{l}\text { Stage I: incorporates engagement of staff, nominating } \\
\text { champions and leaders and project planning (such as how } \\
\text { to manage staff, how to assess willingness for change, } \\
\text { developing a strategy to drive change) } \\
\text { Stages 2-6: involvement of staff in these stages helps to } \\
\text { identify and reinforce team attributes that will drive change }\end{array}$ \\
\hline Skills & $\begin{array}{l}\text { A clinical educator role was seen as essential in providing } \\
\text { supervision and guidance to all staff including the PA. The } \\
\text { SPA role was facilitated by a leader with formal training } \\
\text { experience who was able to break down the role into } \\
\text { discrete competencies, and develop competencies for } \\
\text { the role where none existed previously. Lack of previous } \\
\text { experience working with an assistant can make staff } \\
\text { uncomfortable "letting go" of their work }\end{array}$ & $\begin{array}{l}\text { Stage I: includes project planning, which involves identifying } \\
\text { trainers. Also awareness raising identifies champions for } \\
\text { change. Stage 5: aids planning around supporting systems } \\
\text { such as supervisors. } \\
\text { Stage 6: Includes training trainers and developing links with } \\
\text { training providers }\end{array}$ \\
\hline $\begin{array}{l}\text { Overall strategic } \\
\text { direction, nationally, } \\
\text { locally and } \\
\text { professionally }\end{array}$ & $\begin{array}{l}\text { At a national strategic level, Health Workforce Australia } \\
\text { (HWA) established several broad policy directions } \\
\text { around the introduction of new roles, including assistant } \\
\text { roles. The relatively small numbers of people accessing } \\
\text { the PA training precluded investment in and further } \\
\text { development of training packages for the PA and } \\
\text { OTAP. The podiatry and speech pathology professional } \\
\text { associations had developed scope of practice documents, } \\
\text { but no competency frameworks. }\end{array}$ & $\begin{array}{l}\text { Stage I: pre-awareness includes identification of supporting } \\
\text { bodies/resources; links planning with professional/ } \\
\text { government strategic directions } \\
\text { Stage 6: includes identification of local training bodies and } \\
\text { facilitates engagement with them }\end{array}$ \\
\hline
\end{tabular}


Table 3 (Continued)

\begin{tabular}{|c|c|c|}
\hline & Barriers and facilitators & Stage of CF \\
\hline \multicolumn{3}{|l|}{ Relationships } \\
\hline $\begin{array}{l}\text { Training } \\
\text { organization }\end{array}$ & $\begin{array}{l}\text { Specialized skills required for podiatry training meant } \\
\text { unique requirements that could not easily be met within } \\
\text { the training organization resources. A strong, and } \\
\text { consultative relationship with the training organization } \\
\text { was identified as key to the SPA success. The OTs had } \\
\text { minimal understanding of the training organization and } \\
\text { the specific training undertaken by the OTAPs }\end{array}$ & $\begin{array}{l}\text { Stage I: engagement with all key stakeholders, including the } \\
\text { training organization. Links also with identifying contextual } \\
\text { facilitators and barriers. } \\
\text { Stage } 7 \text { sustaining: links with higher education institutions } \\
\text { are encouraged to develop bespoke training packages for } \\
\text { individuals and organizations }\end{array}$ \\
\hline $\begin{array}{l}\text { Other stakeholders/ } \\
\text { service providers }\end{array}$ & $\begin{array}{l}\text { The enrolled nurses who undertook the role prior to } \\
\text { the introduction of the podiatry assistant role were not } \\
\text { consulted in the implementation process. IMPACT = } \\
>\text { nurses expressed that they felt 'a bit used' and were } \\
\text { disappointed that they would be ceasing the role }\end{array}$ & \\
\hline
\end{tabular}

\section{Discussion}

The process of mapping the data from the three projects against the key steps within the seven stages of the CF identified a number of pertinent steps that could impact on the success of the implementation of new roles. These were: planning and use of a structured approach to change, leadership, service analysis, staff engagement, and consultation, particularly in relation to the scope of the new roles.

A key contextual issue that was identified in all of the evaluations, but is not a part of the CF, was the importance of the policy, regulatory, industrial relations, and professional policy environments to facilitate the introduction of the role (Table 3). The national, local, organizational, and professional policy contexts were all supportive of the introduction of the roles, and in most cases dictated the timing of the approaches and the way the roles were introduced. The $\mathrm{CF}$ tends to focus at an organizational level; however, the external contexts are important considerations for the feasibility and sustainability of new roles.

The new role projects all identified that project planning and change management are important facilitators of the implementation of new roles. These domains are implicit in all of the seven stages of the CF; however, to ensure that these elements are given the priority that they deserve, the $\mathrm{CF}$ could be strengthened by giving them greater emphasis in stage one.

By necessity, the CF is structured around a task-based delegation approach. This approach is difficult to avoid when an established team is developing and introducing a new role based on a framework in which new roles are created by delegating tasks from the existing workforce. However, this creates a situation in which the roles and competencies are very much externally driven and imposed, has the potential to limit career development opportunities of the new worker, and establishes a power and dependency dynamic between the workers. The task-focused, competency-based model also has the effect of creating a "ceiling" around the tasks that can be performed by the assistant rather than allowing an experientially based emergence of the role. The fact that the assistants in all three studies felt confident in the understanding of their own role boundaries should make some allowance for the responsible practice of the assistants within a supporting framework rather than continually reinforcing the traditional hegemonic approach. To a certain extent, these hierarchical structures are also reinforced in existing industrial classifications and professional regulation. ${ }^{43}$

This application of the CF as a tool to appraise three completed evaluations of the introduction of new roles from the UK and Australia has provided a framework for the systematic comparison of other approaches than the CF used for workforce development. It has also provided evidence of the effectiveness of the CF as a workforce planning and development tool, with clear consequences for those aspects of the CF that are not met.

This research demonstrates that the $\mathrm{CF}$ is a valuable tool for both directing workforce change and evaluating the effectiveness of implementation using other tools. As such, it can be applied prospectively to assist services to plan their implementation strategy and it can be applied retrospectively to "diagnose" the elements or areas that may have affected the outcome(s) of the implementation of a new role using other workforce development tools.

Key to successful implementation of new roles is the use of and identification of a framework prior to starting the process. Other examples have been developed recently, such as the guidelines from Alfred Health to introducing new allied health assistant roles, ${ }^{36}$ which embeds several of the principles included in the $\mathrm{CF}$ using a change management 
framework as the organizing structure of the tool. Another comprehensive resource for the introduction of assistant practitioner roles is the East Midlands Assistant Practitioner Toolkit. $^{37}$

As well as embedding key workforce change elements (leadership, planning, service analysis, and engagement), this evaluation identified further, more discreet, elements that the CF contains that can influence the success of new role implementation, in particular where assistants are concerned. These included a targeted recruitment strategy, adequate and appropriate resourcing, relationships with the training organization, the need to engage stakeholders in identifying context specific facilitators and barriers to successful implementation, objective and consensus-based decision making on the scope of new roles, and robust governance arrangements to make new roles safe.

\section{Limitations of the study}

The retrospective application of the CF as a diagnostic tool to existing evaluations presents some risks. The study was dependent on the evaluations containing sufficient documentation to be able to "test" the application of the $\mathrm{CF}$ when it was not used as the guiding structure for the implementations. It is possible that the omissions reported are omissions in reporting the evaluations rather than omissions in the way the new role was implemented. Limiting the study to only three evaluations may mean that other items might have been identified if a broader sample had been used. However, the combination of the analytical approach and diversity between the cases has provided a basis for preliminary examination of the $\mathrm{CF}$ as a diagnostic tool for retrospectively evaluating workforce change. Additionally, applying the CF retrospectively enabled the consequences of not using a structured tool in the implementation process to be determined. Finally, this study has only examined the application of the CF to assistant and assistant practitioner roles. It is likely that the same principles would apply within any delegation framework; however, this remains to be tested within other studies.

\section{Conclusion}

The retrospective application of the $\mathrm{CF}$ as a diagnostic tool to assess a series of workforce change evaluations has demonstrated the value of applying a structured tool in the implementation of workforce change, and the outputs of that change. From this perspective, the $\mathrm{CF}$ is a valuable tool for the development and implementation of new assistant practitioner roles. The $\mathrm{CF}$ is being applied increasingly in different contexts internationally. This type of workforce change tool is in its infancy, and there are limited accounts of this, or similar tools available in the literature. There is a need for further published accounts of applications of the tool to promote an improved understanding of the mechanisms for successful workforce change and the relationships between the processes involved.

\section{Disclosure}

The authors report no conflicts of interest in this work.

\section{References}

1. Australian Institute of Health and Welfare. Life Expectancy and Disability in Australia 1998 to 2003. Canberra: Australian Institute of Health and Welfare; 2006.

2. Department of Human Services, State Government of Victoria. Better Skills, Best Care: Department of Human Services Workforce Design Strategy. Melbourne: Department of Human Services; 2005.

3. Nancarrow SA, Borthwick AM. Dynamic professional boundaries in the healthcare workforce. Sociol Health Illn. 2005;27(7):897-919.

4. Moran A, Enderby P, Nancarrow S. Defining and identifying common elements of and contextual influences on the roles of support workers in health and social care: a thematic analysis of the literature. $J$ Eval Clin Pract. 2011;17(6):1191-1199.

5. Lizarondo L, Kumar S, Hyde L, Skidmore D. Allied health assistants and what they do: a systematic review of the literature. J Multidiscip Healthc. 2010;3:143-153.

6. Moran A, Nancarrow S, Enderby P, Bradburn M. Are we using support workers effectively? The relationship between patient and team characteristics and support worker utilisation in older people's communitybased rehabilitation services in England. Health Soc Care Community. 2012;20(5):537-549.

7. Nancarrow SA, Enderby P, Moran AM, et al. The Relationship Between Workforce Flexibility and the Costs and Outcomes of Older Peoples' Services. London: National Institute of Health Research; 2010.

8. Nancarrow SA, Moran A. Mechanisms For Successful Workforce Change: Spotlight On Allied Health Assistants Working With Older People In The Community. Paper presented at: Primary Health Care Research Conference; July 18-20, 2012; Canberra, Australia.

9. Nancarrow S, Mackey H. The introduction and evaluation of an occupational therapy assistant practitioner. Aust Occup Ther J. 2005;52(4):293-301.

10. Mackey H, Nancarrow S. Report on the Introduction and Evaluation of an Occupational Therapy Assistant Practitioner. Stoke-on-Trent: North Staffordshire Combined Healthcare Trust; 2004.

11. Taylor L, Birch J. Chemotherapy support worker role - a one-year pilot. Cancer Nurs Pract. 2004;3(10):23-27.

12. Nancarrow S. Dynamic role boundaries in intermediate care services. J Interprof Care. 2004;18(2):141-151.

13. Ottley E, Clarke G, McGill M, Tongue A; Changing Workforce Programme. The Accelerated Development Programme for Support Workers in Intermediate Care. London: NHS Modernisation Agency; 2004.

14. Wheatley I. The nursing practice of taking level 1 patient observations. Intensive Crit Care Nurs. 2006;22(2):115-121.

15. Baldwin J, Roberts JD, Fitzpatrick J, While A, Cowan DT. The role of the support worker in nursing homes: a consideration of key issues. J Nurs Manag. 2003;11(6):410-420.

16. Hancock H, Campbell S, Ramprogus V, Kilgour J. Role development in health care assistants: the impact of education on practice. $J$ Eval Clin Pract. 2005;11(5):489-498. 
17. Brandon D, Morris L. Changing Light Bulbs? Research Into the Role of Mental Health Support Workers in East Suffolk: Executive Summary. London: Mental After Care Association; 2002.

18. Shield F. Developing a therapy-led community rehabilitation team. J Integr Care. 1998;6(4):160-168.

19. Ellis B, Connell N. Factors determining the current use of physiotherapy assistants: views on their future role in the South and West UK region. Physiotherapy. 2001;87(2):73-82.

20. Hek G, Singer L, Taylor P. Cross-boundary working: a generic worker for older people in the community. Br J Community Nurs. 2004;9(6):237-244.

21. Ormandy P, Long AF, Hulme CT, Johnson M. The role of the senior health care worker in critical care. Nurs Crit Care. 2004;9(4):151-158.

22. Mackey H. Assistant practitioners: issues of accountability, delegation and competence. Int J Ther Rehabil. 2005;12(8):331-338.

23. Stanmore E, Waterman H. Crossing professional and organizational boundaries: the implementation of generic rehabilitation assistants within three organizations in the northwest of England. Disabil Rehabil. 2007;29(9):751-759.

24. Spilsbury K, Meyer J. Making claims on nursing work: exploring the work of healthcare assistants and the implications for registered nurses' roles. J Res Nurs. 2005;10(1):65-83.

25. Bowman S, Bray K, Leaver G, Pilcher T, Plowright C, Stewart L. Health care assistants' role, function and development: results of a national survey. Nurs Crit Care. 2003;8(4):141-148.

26. Chang AM, Lam LW. Evaluation of a health care assistant pilot programme. J Nurs Manag. 1997;5(4):229-236.

27. Perry M, Carpenter I, Challis D, Hope K. Understanding the roles of registered general nurses and care assistants in UK nursing homes. J Adv Nurs. 2003;42(5):497-505.

28. Warne T, McAndrew S. The mental health assistant practitioner: an oxymoron? J Psychiatr Ment Health Nurs. 2004;11(2):179-184.

29. Johnson M, Ormandy P, Long A, Hulme C. The role and accountability of senior health care support workers in intensive care units. Intensive Crit Care Nurs. 2004;20(3):123-132.
30. McKenna HP, Hasson F, Keeney S. Patient safety and quality of care: the role of the health care assistant. J Nurs Manag. 2004;12(6):452-459.

31. Carr SM, Pearson PH. Delegation: perception and practice in community nursing. Prim Health Care Res Dev. 2005;6(1):72-81.

32. Mackey H. An extended role for support workers: the views of occupational therapists. Int J Ther Rehabil. 2004;11(6):259-266.

33. Duffin C. Accountability and skill mix "at risk" in new job. Nurs Stand. $2003 ; 18(5): 6$.

34. Storey L. Delegation to health care assistants. Pract Nurs. 2005; 16(6):294-296.

35. Wainwright TA. The perceived function of health care assistants in intensive care: nurses views. Intensive Crit Care Nurs. 2002;18(3): 171-180.

36. Alfred Health. Guidelines to Scope and Introduce New Allied Health Assistant Roles. Melbourne: Department of Health; 2012.

37. Wilson M. East Midlands Assistant Practitioner Project: Assistant Practitioner Toolkit. Sandiacre: NHS East Midlands; 2010.

38. Nancarrow S, Enderby P, Ariss S, Parker SG, Campbell M. Enhancing the Effectiveness of Interdisciplinary Team Working. London: National Institute for Health Research; 2012.

39. Smith R, Duffy J. Developing a competent and flexible workforce using the Calderdale Framework. Int J Ther Rehabil. 2010;17(5): 254-262.

40. Kaltner M, Pighills A, Wilson J. A Controlled Clinical Trial Evaluation Of Shared Competencies And Delegation Practice In An Acute Medical Setting. Paper presented at: 7th Health Services Research and Policy Conference; December 5-7, 2011; Adelaide, Australia.

41. Skills for Health; 2010. Available from: www.skillsforhealth.org.uk. Accessed November 7, 2012.

42. Ritchie J, Spencer L. Qualitative data analysis for applied policy research. In: Bryman A, Burgess RG, editors. Analyzing Qualitative Data. London: Routledge; 1995:174-194.
Journal of Multidisciplinary Healthcare

\section{Publish your work in this journal}

The Journal of Multidisciplinary Healthcare is an international, peerreviewed open-access journal that aims to represent and publish research in healthcare areas delivered by practitioners of different disciplines. This includes studies and reviews conducted by multidisciplinary teams as well as research which evaluates the results or conduct of such teams or

\section{Dovepress}

healthcare processes in general. The journal covers a wide range of areas and welcomes submission from practitioners at all levels, from all over the world. The manuscript management system is completely online and includes a very quick and fair peer-review system. Visit http://www.dovepress.com/testimonials.php to read real quotes from published authors. 